\title{
Second-line therapy for disseminated small-cell lung cancer: optimal management remains to be defined
}

\author{
Christos Chouaïd $^{1,2}$, Nathalie Baize ${ }^{3}$, Isabelle Monnet ${ }^{1,2}$ \\ ${ }^{1}$ Univ Paris Est Créteil, INSERM, IMRB, Equipe CEpiA, 94010 Créteil, France; ${ }^{2}$ Service de Pneumologie, Centre Hospitalier Intercommunal de \\ Créteil, Créteil, France; ${ }^{3}$ Service de Cancérologie, CHU d'Angers, Angers, France \\ Correspondence to: Christos Chouaï, MD. CHI Créteil, 40, avenue de Verdun, 94010 Créteil, France. Email: christos.chouaid@chicreteil.fr. \\ Comment on: Zhao Y, Wan B, Zhang T, et al. Irinotecan, topotecan, paclitaxel or docetaxel for second-line treatment of small cell lung cancer: a \\ single-center retrospective study of efficiency comparation and prognosis analysis. Transl Lung Cancer Res 2019;8:829-37.
}

Submitted Feb 29, 2020. Accepted for publication Apr 28, 2020.

doi: $10.21037 /$ tlcr-20-362

View this article at: http://dx.doi.org/10.21037/tlcr-20-362

Lung cancer remains an important public health concern for both men and women, with significant morbidity and mortality. Small-cell lung cancer (SCLC) represents between $14 \%$ and $18 \%$ of all lung cancers. Two thirds are disseminated stages at diagnosis. Management of main SCLC is based on chemotherapy and platin-etoposide combination represents the therapeutic cornerstone for both localized and extensive disease (1). More recently, two pivotal phase 3 trials obtained promising results with the association of platinum-based chemotherapy and immunotherapy, either atezolizumab (2) or durvalumab (3). These chemotherapies or combination of immunotherapy and chemotherapies provide high objective response rates (ORR), but the majority of patients relapse. Second-line treatment for SCLC remains a challenge $(4,5)$.

In this second line setting, particular attention must be paid, in these patients who have a poor prognosis, to the quality of life but also to economic issues. In most randomized-controlled trials, ORR was observed in less than a quarter of patients and median overall survival (OS) range from 3.2 to 8.7 months. The factors associated with outcomes appeared to be associated with the type of firstline chemotherapy, the response to it (resistant, refractory or sensitive), treatment-free period and performance status at relapse (5).

Few real-life studies have provided data on treatment efficacy in non-selected patients (6). Filling that gap, Zhao et al. (7) analyzed the results of 116 SCLC patients treated after a first line platin chemotherapy progression. The main chemotherapy regimens analyzed were irinotecan, topotecan, paclitaxel or docetaxel. Their respective progression-free survival (PFS) durations were comparable, at 3, 2.5, 2.7 or 1.7 months, but OS differed significantly for irinotecan, with 19 vs. 5, 5.6, or 6.1 months, respectively. In that analysis, the ORR to second-line therapy was positively associated with the response to first-line therapy $(\mathrm{P}=0.012)$. According to their multivariate analyses, treatmentfree interval $<90$ days, lactate dehydrogenase $\geq 225 \mathrm{U} / \mathrm{L}$ and neutrophil-to-lymphocyte ratio (NLR) $\geq 3.5$ were independent risk factors for poor OS.

That study had numerous limitations, particularly its retrospective design and monocenter setting. Even though it was a real-life study, the inclusion modalities did not allow us to know the number of patients who did not receive second-line therapy because of poor general conditions and, thus, the degree of selection of those analyzed.

In real life setting, many SCLC patients do not receive second-line therapy. According to a German study (8), among the 432 consecutively included patients with advanced disease at diagnosis, only $50 \%$ of them received second-line therapy. In a Swedish mono-centric analyse (9) of 544 patients_-408 metastatic and 136 with localized at diagnosis-only a quarter of the former received secondline therapy, with the rest given best supportive care (BSC). Median OS after starting second-line therapy was 10.2 and 4.4 months, respectively, for patients with sensitive or resistant SCLC. For patients with localized disease at diagnosis, only one-third of patients with received secondline treatment, which achieved a median PFS of 4.8 months and median OS of 8.2 months. 
The results of all those studies confirmed the poor prognoses of these patients and the weak efficacy of the currently available therapeutic options, despite numerous combinations having been investigated in the second-line setting (10-18).

Oral Topotecan chemotherapy, in a randomized study (11) was compare to best supportive care for SCLC patients progressing after a first line chemotherapy and not eligible for standard second-line IV chemotherapy. Topotecan group showed significantly longer OS and a significant better QOL for; in this arm, 7\% of the patients had a ORR and $44 \%$ a stabilization; the median OS durations were 6.5 vs. 2.4 months for topotecan and BSC, respectively.

Cyclophosphamide, doxorubicin and vincristine (CAV) used as second-line treatment after cisplatin-etoposide obtained response rates of $13-28 \%$ (13); intravenous (IV) and oral topotecan yielded similar results (17). To preserve the quality of life, several teams have analyzed the interest of oral chemotherapies (14). Prolonged daily oral etoposide was first used for refractory or relapsed SCLC. Lomustine (CCNU) was extensively prescribed to treat SCLC in the 1980s, with promising efficacy, the difficulty to use it with radiotherapy limited its use. In a retrospective analysis including 35 patients, the ORR obtained with the combination of oral etoposide, lomustine and cyclophosphamide, was $74 \%$, with median OS at 4.4 months and acceptable safety (14). The effectiveness of this oral chemotherapy treatment, given in an outpatient setting, resulted to the implementation of a randomized III trial with a IV administration comparison. This study compared second-line oral chemotherapy (CCNU, cyclophosphamide, etoposide) vs. an IV regimen of CAV for patients with relapsed sensitive SCLC. No significant difference was found between the two arms for PFS ( 3 and 3.1 , respectively) or OS (6.1 and 5.8, respectively) (15).

Phase II trials have tested various other drugs, e.g., pemetrexed and amrubicin (a third-generation anthracycline) but, unfortunately, most of these trials were disappointing (5). In a phase 2 study, amrubicin obtained a significantly higher ORR than topotecan $(44 \%$ vs. $15 \% ; \mathrm{P}=0.021)$, with respective median OS lasting 9.2 vs. 7.6 months and similar tolerance for both drugs. For patients with refractory SCLC, median OS was 6.0 months but outcomes of the phase III trial that randomized 637 patients to receive amrubicin or topotecan were negative, with no OS difference between the two arms (7.5 vs. 7.8 months) $(12,16)$.

The last few years have seen investigations on the roles of new drugs and targeted therapies for SCLC, in majority in the first-line setting but also in some cases in patients with relapsed disease. The combination of bevacizumab and paclitaxel for relapsed SCLC was assessed in a phase II study. The disease-control rate was $66 \%(11.1 \%$ of ORR and, $55.5 \%$ of stable disease rate); median OS was 5 months (5). Outcomes for these patients with growth factor-receptor inhibitors have been disappointing (5).

Administering second-line chemotherapy to SCLC patients who relapsed within 3 months, i.e., sensitive disease, remains controversial (18-20). In this setting, ORRs after first-line treatment with CAV and IV topotecan were, respectively, $24.3 \%$ and $18.3 \%$, and median OS was 6 months for both arms (5). Using oral topotecan, ORRs were $18.3 \%$ and median survival was 8.5 months but, only $10 \%$ of the study population had relapsed during the 3 months following the end of first-line treatment. In an open-label, multicenter, phase 3 trial (21), 162 patients, whose SCLCs had responded to first-line platinumetoposide doublet but relapsed or progressed at least 90 days after completing that therapy, were randomized (1:1) to receive combination chemotherapy or oral topotecan. The primary endpoint was PFS analyzed with a onesided $\alpha$ of $5 \%$ for the intention-to-treat population. The main secondary endpoints were ORR, OS and treatment-related adverse events (21). Comparing combination chemotherapy recipients to the topotecan group, respectively: median PFS was significantly longer (4.7 vs. 2.7 months; hazard ratio: 0.6; 95\% CI: 0.4-0.8; $\mathrm{P}<0.001)$; ORR was significantly higher $(49.4 \%$ vs. $25.3 \%$; $\mathrm{P}=0.002)$; median OS durations were comparable (7.5 and 7.4 months, respectively; $\mathrm{P}=0.936$ ); grade $3-4$ neutropenia was less frequent $(19.7 \%$ vs. $35.8 \% ; \mathrm{P}<0.035)$; and 0 vs. 2 deaths (febrile neutropenia with sepsis) were attributed to treatment.

Those results suggest that platinum-etoposide reintroduction can be considered a standard second-line chemotherapy for sensitive relapsed SCLC (21).

Finally, contrasting results have been obtained with immunotherapy in this context. CheckMate-032 (22), a phase I/II open-label trial randomized 216 patients to receive nivolumab alone or nivolumab + ipilimumab $(1 \mathrm{mg} / \mathrm{kg}$ + $3 \mathrm{mg} / \mathrm{kg}$, or $3 \mathrm{mg} / \mathrm{kg}+1 \mathrm{mg} / \mathrm{kg}$ ). ORRs were achieved in $10 \%, 23 \%$ and $19 \%$ of the patients treated, respectively, with nivolumab alone, nivolumab + ipilimumab: $1 \mathrm{mg} / \mathrm{kg}$ $+3 \mathrm{mg} / \mathrm{kg}$ or $3 \mathrm{mg} / \mathrm{kg}+1 \mathrm{mg} / \mathrm{kg}$. The safety profile was manageable, with few treatment-related toxic effects for all regimens. On the other hand, nivolumab, in an open-label 
phase III trial (23), vs. standard-of-care chemotherapy as second-line treatment for patients with SCLC progressing after first-line platinum-based chemotherapy, failed to meet its primary OS endpoint. Atezolizumab, in a phase II trial, of second-line treatment failed also to meet its primary endpoint of increased ORR vs. standard of care (i.e., topotecan or carboplatin-etoposide reinduction, left to the investigator's choice) (24). Median PFS was 1.4 months for the atezolizumab group and 4.2 months for the chemotherapy arm, with the experimental arm having an unfavorable risk of progression (hazard ratio 2.26; $\mathrm{P}=0.004)$.

Association of immunotherapy and chemotherapies have also been evaluated after platinum-etoposide failure. Paclitaxel, $175 \mathrm{mg} / \mathrm{m}^{2}, \mathrm{~d} 1-\mathrm{d} 21$, up to 6 cycles and flatdose pembrolizumab (200 $\mathrm{mg}$ every 3 weeks), added at the second cycle until disease progression or unacceptable toxicity, in refractory metastatic SCLC patients was evaluated in a phase II study. ORR was $23.1 \%$, with a disease control rate exceeding $80 \%$ and median OS at 9.2 months. Toxicity was acceptable; the main grade 3-4 events, e.g., febrile neutropenia, were chemotherapyrelated (25).

Optimal management of second-line therapy for SCLC remains to be defined, particularly for patients whose disease is refractory or resistant to first-line platinum doublet. Real-life studies, when they are of good quality, particularly when based on exhaustive cohorts, enable us to better understand the results obtained from clinical trials.

\section{Acknowledgments}

Funding: None.

\section{Footnote}

Provenance and Peer Review: This article was commissioned by the editorial office, Translational Lung Cancer Research. The article did not undergo external peer review.

Conflicts of Interest: All authors have completed the ICMJE uniform disclosure form (available at http://dx.doi. org/10.21037/tlcr-20-362). CC reports grants, personal fees and non-financial support from Roche, Amgen, MSD, BMS, Takeda, Pfizer, Novartis, Health Accord, MundiPharma, Janssen, Bayer, Mylan, outside the submitted work. The other authors have no conflicts of interest to declare.
Ethical Statement: The authors are accountable for all aspects of the work in ensuring that questions related to the accuracy or integrity of any part of the work are appropriately investigated and resolved.

Open Access Statement: This is an Open Access article distributed in accordance with the Creative Commons Attribution-NonCommercial-NoDerivs 4.0 International License (CC BY-NC-ND 4.0), which permits the noncommercial replication and distribution of the article with the strict proviso that no changes or edits are made and the original work is properly cited (including links to both the formal publication through the relevant DOI and the license). See: https://creativecommons.org/licenses/by-nc-nd/4.0/.

\section{References}

1. Tsoukalas N, Aravantinou-Fatorou E, Baxevanos P, et al. Advanced small cell lung cancer (SCLC): new challenges and new expectations. Ann Transl Med 2018;6:145-51.

2. Horn L, Mansfield AS, Szczesna A, et al. First-Line Atezolizumab plus Chemotherapy in Extensive-Stage Small-Cell Lung Cancer. N Engl J Med 2018;379:2220-9.

3. Paz-Ares L, Dvorkin M, Chen Y, et al. Durvalumab plus platinum-etoposide versus platinum-etoposide in firstline treatment of extensive-stage small-cell lung cancer (CASPIAN): a randomised, controlled, open-label, phase 3 trial. Lancet 2019;394:1929-39.

4. Owonikoko TK, Behera M, Chen Z, et al. A systematic analysis of efficacy of second-line chemotherapy in sensitive and refractory small-cell lung cancer. J Thorac Oncol 2012;7:866-72.

5. Baize N, Monnet I, Greillier L, et al. Second-line treatments of small-cell lung cancers. Expert Rev Anticancer Ther 2017;17:1033-43.

6. Garassino MC, Torri V, Michetti G, et al. Outcomes of small-cell lung cancer patients treated with second-line chemotherapy: a multi-institutional retrospective analysis. Lung Cancer 2011;72:378-83.

7. Zhao Y, Wan B, Zhang T, et al. Irinotecan, topotecan, paclitaxel or docetaxel for second-line treatment of small cell lung cancer: a single-center retrospective study of efficiency comparation and prognosis analysis. Transl Lung Cancer Res 2019;8:829-37.

8. Steffens CC, Elender C, Hutzschenreuter U, et al. Send to Treatment and outcome of 432 patients with extensivestage small cell lung cancer in first, second and third line - 
Results from the prospective German TLK cohort study. Lung Cancer 2019;130:216-25.

9. Tendler S, Zhan Y, Pettersson A, et al. Treatment patterns and survival outcomes for small-cell lung cancer patients - a Swedish single center cohort study. Acta Oncol 2020;59:388-94.

10. Igawa S, Shirasawa M, Ozawa T, et al. Comparison of carboplatin plus etoposide with amrubicin monotherapy for extensive-disease small cell lung cancer in the elderly and patients with poor performance status. Thorac Cancer 2018;9:967-73.

11. O'Brien ME, Ciuleanu TE, Tsekov H, et al. Phase III trial comparing supportive care alone with supportive care with oral topotecan in patients with relapsed small-cell lung cancer. J Clin Oncol 2006;24:5441-7.

12. Jotte R, Conkling P, Reynolds C, et al. Randomized phase II trial of single-agent amrubicin or topotecan as secondline treatment in patients with small-cell lung cancer sensitive to first-line platinum-based chemotherapy. J Clin Oncol 2011;29:287-93.

13. von Pawel J, Schiller JH, Shepherd FA, et al. Topotecan versus cyclophosphamide, doxorubicin, and vincristine for the treatment of recurrent small-cell lung cancer. J Clin Oncol 1999;17:658-67.

14. Lebeau B, Chouaïd C, Baud M, et al. Oral secondand third-line lomustine-etoposide-cyclophosphamide chemotherapy for small cell lung cancer. Lung Cancer 2010;67:188-93.

15. Gervais R, Le Caer H, Monnet I, Second-line oral chemotherapy (lomustine, cyclophosphamide, etoposide) versus intravenous therapy (cyclophosphamide, doxorubicin, and vincristine) in patients with relapsed small cell lung cancer: a randomized phase II study of GFPC 0501. Clin Lung Cancer 2015;16:100-5.

16. von Pawel J, Jotte R, Spigel DR, et al. Randomized phase III trial of amrubicin versus topotecan as second-line treatment for patients with small-cell lung cancer. J Clin Oncol 2014;32:4012-9.

17. Eckardt JR, von Pawel J, Pujol JL, et al. Phase III study of oral compared with intravenous topotecan as second- line therapy in small-cell lung cancer. J Clin Oncol 2007;25:2086-92.

18. Genestreti G, Tiseo M, Kenmotsu H, et al. Outcomes of Platinum-Sensitive Small-Cell Lung Cancer Patients Treated With Platinum/Etoposide Rechallenge: A MultiInstitutional Retrospective Analysis. Clin Lung Cancer 2015;16:e223-8.

19. Goto K, Ohe Y, Shibata T, et al. Combined chemotherapy with cisplatin, etoposide, and irinotecan versus topotecan alone as second-line treatment for patients with sensitive relapsed small-cell lung cancer (JCOG0605): a multicentre, open-label, randomised phase 3 trial. Lancet Oncol 2016;17:1147-57.

20. Postmus PE, Berendsen HH, van Zandwijk N, Splinter TA, Burghouts JT, Bakker W. Retreatment with the induction regimen in small cell lung cancer relapsing after an initial response to short term chemotherapy. Eur J Cancer Clin Oncol 1987;23:1409-11.

21. Baize N, Monnet I, Greillier L. Carboplatin-Etoposide Versus Topotecan as Second-Line Treatment for Sensitive Relapsed Small-Cell Lung Cancer: Phase 3 Trial. J Thorac Oncol 2019;10:S246.

22. Ready NE, Ott PA, Hellmann MD, et al. Nivolumab Monotherapy and Nivolumab Plus Ipilimumab in Recurrent Small Cell Lung Cancer: Results From the CheckMate 032 Randomized Cohort. J Thorac Oncol 2020;15:426-35.

23. Verma V, Sharma G, Singh A. Immunotherapy in extensive small cell lung cancer. Exp Hematol Oncol 2019;8:5.

24. Pujol JL, Greillier L, Audigier-Valette C, et al. A Randomized Non-Comparative Phase II Study of AntiProgrammed Cell Death-Ligand 1 Atezolizumab or Chemotherapy as Second-Line Therapy in Patients With Small Cell Lung Cancer: Results From the IFCT-1603 Trial. J Thorac Oncol 2019;14:903-13.

25. Kim YJ, Keam B, Ock CY et al. A phase II study of pembrolizumab and paclitaxel in patients with relapsed or refractory small-cell lung cancer. Lung Cancer 2019;136:122-8.
Cite this article as: Chouaïd C, Baize N, Monnet I. Secondline therapy for disseminated small-cell lung cancer: optimal management remains to be defined. Transl Lung Cancer Res 2020;9(5):1732-1735. doi: 10.21037/tlcr-20-362 